\title{
Health policy and its unintended consequences for midwife-woman partnerships: Is normal pregnancy at risk when the BMI measure is used?
}

\author{
Susan Knox ${ }^{A, B}$ PhD (Cand), MHSC, PGDip HPromoHEd, BSC (Mid) • Susan Crowther' PhD, MSC, BSC \\ (Hons), RM, RN • Judith McAra-Couper ${ }^{B}$ PhD, PGDipEd, BA, DipMid, RGON • Andrea Gilkison ${ }^{B}$ PhD, \\ MEd (Dist), BSocSci, RM, RCpN
}

\author{
A Corresponding \\ Author: suknox@aut. \\ ac.nz \\ ${ }^{\text {B }}$ Centre for \\ Midwifery and \\ Women's Health \\ Research, Auckland \\ University of \\ Technology \\ ${ }^{\mathrm{C}}$ Robert Gordon \\ University, Scotland
}

\begin{abstract}
Background: Little attention has been paid to understanding the unintended consequences of health policy for midwife-woman partnerships. The measure of Body Mass Index (BMI) is one such policy example which has become established in contemporary midwifery practice as a tool for assessing pregnancy risk. The universal acceptance of BMI creates an unsettling paradox for midwives concerned with promoting woman-centred practice. The increasing focus on BMI is challenging for midwives as they navigate ethical tensions when directed to undertake practices which have potential unwonted consequences for the midwife-woman partnership.
\end{abstract}

Aim: The aim of the study was to explore the use of an indicator, using BMI as an example, to provide an international perspective on obesity prevention policy and maternity care provision.

Method: A comparative case study approach was taken, using descriptive cross-national comparative analysis of obesity prevention policy, weight management guidelines and midwifery models of care in New Zealand and Scotland.

Discussion: Despite promoting healthy weight gain in pregnancy, New Zealand and Scottish health policies may be missing health promotion opportunities. Focusing on BMI in maternity, per se, should not prohibit other assessment of lifestyle issues or delivery of services based on individual needs, capacities, histories and sociological characteristics. Relying solely on pre-pregnancy BMI as a marker of health in all women has remained relatively unchallenged and, as such, constitutes a policy problem because it occludes the factoring in of other lifestyle issues that may significantly alter individual risk status. Further, such an assessment of risk status is ideally arrived at within a partnership model of maternity care, rather than reliance on an a priori medical test.

Conclusion: Decontextualised policies are challenging for midwives where medical and midwifery values are in conflict. Policy which fails to consider the multiple and complex contexts of women's lives is confronting for midwives as they attempt to re-articulate the meaning of woman-centred practice. Furthermore, BMI as a tool may be ineffectual. The current focus on BMI in policy and practice requires re-consideration.

Keywords: midwifery partnership, health policy, weight management guidelines, BMI, New Zealand, Scotland

\section{INTRODUCTION}

Little attention has been paid to understanding the unintended consequences of health policy for midwife-woman partnerships. Torloni, Betran, and Merialdi (2012) highlighted how maternal obesity is a real concern in pregnancy. Evidence shows that maternal obesity significantly increases the risk of adverse maternal and infant outcomes (Marchi, Berg, Dencker, Olander, \& Begley, 2015) and of admissions for specialist care (Denison et al., 2014). The growing evidence has led to obesity-targeted policy recommendations in New Zealand and Scotland (Ministry of Health, 2015b; Scottish Government, 2010; Scottish Government, 2011), yet little is known about the potential impact of such policies on midwifery practice. The measure of Body Mass Index (BMI) is one such policy example which has become established in contemporary midwifery practice as a tool for assessing pregnancy risk. One unintended consequence of such policy, and its associated gestational weight management guidelines, is an apparent preoccupation with weight surveillance. Such a focus on weight rather than pregnancy lifestyle care, in turn can pathologise the whole pregnancy for the woman.

BMI was originally intended as a tool used to monitor progress towards government targets on overweight and obesity (Hall \& Cole, 2006). Subsequently, BMI has been widely adopted in policy and practice as a tool for individual assessment of overweight and obesity during pregnancy (Institute of Medicine, \& National Research Council, 2009). BMI is therefore now used as the sole method of weight-based risk stratification in pregnancy. We are not disputing that BMI can be useful when used across populations but contest its use as the sole basis of risk stratification. We are concerned that the use of the BMI measurement alone may fail to 
consider or recognise that some women are overweight and remain healthy. Their BMI is often the dominating focus of their care plan, when what matters most to women is a positive care experience based on compassion, choice and dignity (Morad, Parry-Smith, \& McSherry, 2013). This appears to contradict the bespoke nature of care. Thus, the intrusive BMI is one such case that highlights a tension between individualised care to women juxtaposed to the routine nature of the dominant policy approaches to weight management. It is timely to expose a pathological paradox in which, if they have a BMI $\geq 25 \mathrm{~kg} / \mathrm{m}^{2}$, this is understood as always abnormal, covering up that some of these women are actually enjoying a healthy pregnancy. In other words, the BMI-related policy implication is that this places all women with a BMI over 25 as at risk, which leads to standardisation of care and may be moving us away from our focus on women-centred, individualised care.

The aim of our paper is to explore the use of an indicator, using BMI as an example, to provide an international perspective on policy and maternity care provision. New Zealand and Scotland are used for comparison as they are two countries with high-income economies and are served by well-educated, regulated, registered, health care practitioners. Both countries have persisting disparities in socio-economic statuses and a rising obesity prevalence within low-income populations, which are growing causes for concern (Ministry of Health, 2015b; Scottish Government, 2010). See Table 1 for the comparison of prevalences between the two countries.

Table 1. Comparative demographics between adults in New Zealand and Scotland

\begin{tabular}{|c|c|c|}
\hline Variable & New Zealand & Scotland \\
\hline $\begin{array}{l}\text { Overweight } \\
\text { and obesity }\end{array}$ & $\begin{array}{l}\text { Overweight (66\%) } \\
\text { Obese (31\%) }\end{array}$ & $\begin{array}{l}\text { Overweight (65\%) } \\
\text { Obese (28\%) }\end{array}$ \\
\hline $\begin{array}{l}\text { Obesity by } \\
\text { gender }\end{array}$ & $\begin{array}{l}\text { Women (32\%) } \\
\text { Men }(29 \%)\end{array}$ & $\begin{array}{l}\text { Women (29\%) } \\
\text { Men }(26 \%)\end{array}$ \\
\hline $\begin{array}{l}\text { Obesity by } \\
\text { ethnicity }\end{array}$ & $\begin{array}{l}\text { Pacific peoples (66\%) } \\
\text { Māori (47\%) } \\
\text { Asian peoples (12\%) }\end{array}$ & $\begin{array}{l}\text { Chinese (4\%) } \\
\text { Asian/Other (9\%) }\end{array}$ \\
\hline $\begin{array}{l}\text { Obesity by } \\
\text { deprivation }\end{array}$ & $\begin{array}{l}\text { Most deprived areas } \\
(42 \%) \\
\text { Least deprived areas } \\
(22 \%)\end{array}$ & $\begin{array}{l}\text { Most deprived areas } \\
(37 \%) \\
\text { Least deprived areas } \\
(21 \%)\end{array}$ \\
\hline
\end{tabular}

Sources: Ministry of Health (2015a) and Scottish Government (2015)

While the countries in terms of obesity prevalence are not vastly different, the issues related to health inequalities, maternity service provision and maternity policy approaches to address obesity are dissimilar. An ideographic approach was chosen to understand each country in its own terms (Kohn, 1989). Each nation was treated as an object of study, and the approach was selected to highlight the unique elements related to maternity service provision and maternity care policy to address obesity. Here, we explore how policy and maternity practice diverge and converge in the two regions. We are particularly concerned with uncovering the unintended consequences of adopting a population tool in woman-centred practice, the potential consequences of which have gone relatively unexplored. By examining two sets of policies across different regions, the salient aspects of the issue related to the routine measurement of BMI in pregnancy can be highlighted. Further, we discuss the tensions evident for midwives as they implement BMI-focused policy while engaging with women in partnership relationships.
This paper begins with a brief overview of relevant literature in relation to obesity and weight gain in pregnancy. We then describe policy measures in New Zealand and Scotland which aim to promote healthy gestational weight gain, before describing how the countries have sought to implement weight management guidelines in pregnancy. This is followed by analysis of each country's midwifery models of care to answer: "How far and in what ways are New Zealand and Scotland promoting womancentred practice in pregnancy?" To conclude, we highlight the lessons drawn and reflect on the challenges of implementing policy in ways which ensure the well-woman focus.

\section{Literature review}

Overweight and obesity are defined as abnormal or excessive fat accumulation that presents a risk to health (World Health Organization, 2015b). The negative impacts associated with overweight and obesity in pregnancy for mothers and their infants are well documented. It is argued that excessive gestational weight gain is the most deleterious consequence of pregnancy (Gilmore, Klempel-Donchenko, \& Redman, 2015). Maternal obesity leads to an increased risk of both gestational diabetes and hypertensive conditions for women and, for the infant, perinatal death, congenital anomalies, birth trauma and high birth weight (Adamo et al., 2013; Catalano \& Ehrenberg, 2006; Dodd, Grivell, Nguyen, Chan, \& Robinson, 2011; Furber et al., 2013; Galtier, Raingeard, Renard, Boulot, \& Bringer, 2008; Galtier-Dereure, Boegner, \& Bringer, 2000; Lashen, Fear, \& Sturdee, 2004; Leslie, Gibson, \& Hankey, 2013; Ramachenderan, Bradford, \& McLean, 2008; Ryan, 2007; Stotland, 2009). Low-income women were found to be more at risk than middle- and high-income women for excessive gestational weight gain, pointing to obesity-related disparities being a growing concern (Yeo \& Logan, 2014). Furthermore, the predisposition to obesity is hereditary and is thought to impact the health of future generations (Mourtakos et al., 2015; Pirkola et al., 2010). Such evidence is fueling interest in pregnancy as a critical period to promote healthy weight gain (Huda, Brodie, \& Sattar, 2010)

Despite pregnancy being an opportunity for health promotion, current obesity prevention initiatives have shown little evidence of success. Questions have been raised about the effectiveness of obesity-related policy approaches, with few of these approaches subject to rigorous evaluation and fewer still showing unequivocal evidence demonstrating efficacy in stabilising or reducing body weight (Essington \& Hertelendy, 2016). It is unsurprising that the weight-focused approach to obesity management is being challenged (Bacon \& Aphramor, 2011; Hafekost, Lawrence, Mitrou, O'Sullivan, \& Zubrick, 2013).

In common with biomedical approaches to weight management, the emphasis on "one size fits all" (Hill et al., 2017) seeks standardised care pathways, neglecting the multiple contexts within which women exist (Keely, Cunningham-Burley, Elliott, Sandall, \& Whittaker, 2017). The International Confederation of Midwives (ICM; 2017a) argues that the provision of maternity care that is service-centred rather than woman-centred can contribute to the medicalisation of pregnancy and childbirth. Inhorn (2006) describes medicalisation as the biomedical tendency to pathologise otherwise normal bodily states, leading to incumbent medical management. Pregnancy is a life event which has been medicalised with pregnant women's experiences epitomising the process of medicalisation (Zadoroznyj, 1999).

BMI appears to be part of the increasing medicalisation of pregnancy, with pregnant women increasingly being viewed through the lens of pathology. Pregnancy is a normal human 
process which, like many processes, can vary from person to person. As such, biological approaches are narrow in focus and minimise opportunities for midwives to enable women to make sense of their health and well-being. Policy has paid little attention to the social context of maternal populations at risk of obesity (Heslehurst et al., 2011). Concurring, Sutherland, Brown and Yelland (2013) suggest that approaches which focus on behaviours that immediately lead to obesity, without considering the social circumstances that shape behaviours, are likely to have limited reach and impact on low-income groups. The rhetoric of personal choice, within which the obesity epidemic debate is framed, makes it difficult to see the structural barriers which encourage poor health or poor diet for women living in unhealthy environments (Cain, 2013). According to Greener, Douglas and van Teijlingen (2010), the prevailing biomedical interventions aim to enhance the health promoting capability of existing services to prevent or reduce obesity. Yet, without evidence from large-scale trials, it remains unclear whether adherence to suggested weight gain ranges improves maternal and infant health (National Institute Health and Clinical Excellence [NICE], 2010).

As sociologist C. Wright Mills (Mills, 1959) famously argued, we need to see personal problems (including and especially medical ones) as public issues and vice versa; it is inadvisable and misleading to see personal issues as separate from their complex historical and social contexts. Further, such approaches as those referred to above, serve to heighten anxiety and increase weight-based stigma (Lindhardt, Rubak, Mogensen, Lamont, \& Joergensen, 2013; Mills, Schmied, \& Dahlen, 2013). Emerging evidence supports the view that focusing on healthy lifestyles rather than on gestational weight is likely to be more effective (Keely et al., 2017; Smith et al., 2015). For example, in her study of women's lived experiences of co-existing BMI >30 and gestational diabetes mellitus, Jarvie (2017) found women sought less directive, more collaborative care. Similarly, findings from a feasibility study, and the degree of acceptability of a brief midwife-led intervention in that study, showed that women welcomed individualised discussion regarding diet and exercise (Warren, Rance, \& Hunter, 2017). Arguably, a greater focus on promoting healthy lifestyles tailored to individual needs and preferences would be more acceptable and aligns more closely with the midwifery model of working in partnership with women.

Midwifery is based upon a partnership between women and midwives which aims to promote healthy outcomes (ICM, 2017b). The ICM Code of Ethics for Midwives (2008) urges midwives to develop a partnership with individual women, in which they actively share information and support women in their right to actively participate in decisions about their care. The midwife's role is to facilitate the safe passage of women and babies through the maternity care system (Koniak-Giffin, 1993), yet policy constraints potentially impact upon this primary midwifery focus, compromising the optimal ability of midwives to support women in achieving a normal pregnancy.

\section{Design}

Comparative analyses of policy and models of care in New Zealand and Scotland are presented. Descriptive cross-national comparisons can provide important new insights (Kan \& Lau, 2013; Room et al., 2013; Shield et al., 2013). Similarly, Musingarimi (2009) conducted a descriptive comparative analysis of obesity-related policies within the devolved administrations in the United Kingdom (UK). We used descriptive methods to analyse related literature, policy and guidelines to explore how policy and practice diverge and converge in the two countries. A literature review was conducted to identify stand-alone policy documents, dated 2010-2016, which propose public health frameworks for action and guidance for weight management during pregnancy in New Zealand and Scotland. We examined pre-conception, pregnancy and postpartum-related policies relating to weight on entering pregnancy and weight gain during pregnancy, paying particular attention to how BMI is used in maternity practice. Case studies outline the high-level policy response and the major lifestyles interventions in place to optimise gestational weight gain. It is not in the scope of this paper to explore how government arrangements affect policy; nor is it our intention to advance understanding of policy processes or identify the successes and failures of the current measures. We do not intend to critique policies for their impacts but rather we seek to understand current approaches and the extent to which policy and maternity guidance supports pregnant women to adopt healthy lifestyles. The following section describes the policy response and models of maternity care in each country as a basis for undertaking a comparative case study.

\section{FINDINGS}

\section{New Zealand case study}

The New Zealand Health Strategy's Roadmap of Actions (Ministry of Health, 2016) lays down a plan to tackle long term conditions and obesity. The recently launched Childhood Obesity Plan (Ministry of Health, 2015b) sets the direction for prevention of, and early intervention to address, obesity. A package of initiatives to prevent and manage obesity in children and young people is being implemented. The initiatives aim to take a life-course and progression of condition approach and include: targeted interventions for those who are obese; increased support for those at risk of becoming obese; and broad approaches to make healthier choices easier for all New Zealanders. The focus is on food, the environment and being active at each life stage, starting during pregnancy and early childhood. Development of the policy drew on national and international evidence outlined in the Interim Report on Ending Childhood Obesity (World Health Organization, 2015a).

The New Zealand maternity care model is unique in that women choose their lead maternity carer (LMC), usually a midwife, who provides continuity of care for women from early pregnancy, through the labour and birth and up to six weeks postpartum (Rowland, McLeod, \& Forese-Burns, 2012). LMC midwives claim from the government for the services they provide, so that maternity services are free to eligible women, unless the woman chooses a private obstetrician, who can charge over and above government funding. This model means that the LMC midwife is able to build a close relationship with a woman and her family/ whānau (extended family group) during her pregnancy, developing trust and preparing the woman for the labour, birth and becoming a parent. Thus, LMC midwives have an opportunity to tap into what is known as that "teachable moment" and potentially effect change to support healthy lifestyles and better outcomes for both the woman and her family (Pan, Dixon, Paterson, \& Campbell, 2014).

Guidance for Healthy Weight Gain in Pregnancy was published to support a reduction in the incidence of "inappropriate" weight gain in pregnancy (Ministry of Health, 2014). This guidance updated the advice provided in the Food and Nutrition Guidelines for Healthy Pregnant and Breastfeeding Women (Ministry of Health, 2006). The advice is to encourage women to monitor their own weight at regular intervals during pregnancy and the postpartum period and discuss this with their LMC as part of their care plan. 
BMI is normally calculated at booking/first visit, ideally before 10 weeks' gestation (Ministry of Health, 2014).

The healthy range for BMI is defined as 18.5 to $25 \mathrm{~kg} / \mathrm{m}^{2}$, with obesity being recognised as a BMI of $30 \mathrm{~kg} / \mathrm{m}^{2}$ or above (World Health Organization, 2015b). Maternal obesity is defined as prepregnancy BMI $\geq 30 \mathrm{~kg} / \mathrm{m}^{2}$ (Chen, Feresu, Fernandez, \& Rogan, 2009). In order to identify overweight and obese women, midwives measure women's BMIs which are calculated through height and weight measurements $\left(\mathrm{kg} / \mathrm{m}^{2}\right)$. Midwives and other providers of maternity care measure women's BMIs at the beginning of pregnancy to guide care and assess risk, given the significantly elevated risk associated with overweight and obesity in pregnancy for both mother and child, as signalled over the past two decades or so. It is expected that dietary and lifestyle advice is offered, or the woman is referred to a specialist, based on her BMI (Ministry of Health, 2012). It is a requirement, for example, to elevate care from low risk to higher risk categories in many hospitals across New Zealand.

Despite the availability of guidance since 2006, little is known about midwives' actual practice in relation to giving advice to women in relation to gestational weight gain. A nationwide cohort study involving 428 midwives described the practices of LMC midwives when discussing nutrition, activity and weight gain during pregnancy (Pan et al., 2014). Findings showed the majority of midwives provided information on nutrition and exercise during pregnancy and measured the height and weight of women in order to determine BMI. However, little is known in New Zealand about how such weight-focused advice leads to behaviour change, or not, in women with a high BMI within a continuity of carer model.

\section{Scotland case study}

Scotland has one of the worst obesity records among Organisation for Economic Cooperation and Deveplopment (OECD) countries (Scottish Government, 2010). A number of government policies and initiatives aimed at addressing obesity are in place there. Maternal obesity in isolation from contextual forces is not the focus. The focus is on improvements within the wider community of Scotland rather than in individuals, or individual groups in isolation (Scottish Government, 2011). In the Prevention of Obesity Route Map (Scottish Government, 2010), the government and the Convention of Scottish Local Authorities (COSLA) outline their long term commitment to tackle overweight and obesity. The goals are to have the majority of Scotland's adult population within a normal weight range and to have fewer overweight or obese children in Scotland. Thus, the majority of policy initiatives are focused on childhood obesity, the school environment and the workplace. The commitment to reducing prevalence of childhood obesity is reinforced by the inclusion of a national indicator to increase the proportion of healthy weight children (Scottish Government, 2011). Following analysis of the Route Map using the ANGELO (Analysis Grid for Environments Linked to Obesity) framework, Mooney, Jepson, Frank and Geddes (2015) found that, while all of the four domains of physical, economic, legislative and socio-cultural influences are represented, there is a disproportionate imbalance of policies in the attitude/behavioural arena compared to the built environment and at the expense of the legislative and economic domains. These authors further argue that, while the picture is unsurprising, it is at odds with the increasing body of international evidence about what works best.

Despite obesity being a UK-wide public health concern, there remains no evidence-based UK guidelines on recommended weight gain ranges during pregnancy (NICE, 2010). The Scottish Government launched Improving Maternal and Infant Nutrition: A Framework for Action in 2011 (Scottish Government, 2011). While this policy recognises the importance of good nutrition before conception, during pregnancy and in the early years, it did not go so far as to publish guidance on what is considered a healthy gestational weight gain. Despite this paucity of evidence on recommended weight gain ranges, direction has been provided at the policy level, not in terms of clear guidelines but as continuous advice on lifestyle and activity levels throughout pregnancy across the UK maternity systems (NICE, 2010). NICE suggests offering supportive specific and practical information to elicit behavioural changes which includes: discussing eating habits and safe physical activity; providing practical and tailored information; dispelling myths about what and how much to eat during pregnancy; measuring weight and height; calculating BMI at the first contact; and being sensitive to any concerns mothersto-be may have about their weight. The advice is to not weigh women repeatedly during pregnancy as a matter of routine but only if clinical management can be influenced or if diet and weight changes become problematic. Offering a referral to a dietitian or appropriately trained health professional is encouraged to support women to lose weight after pregnancy.

The Midwifery 2020 programme emphasises the public health role of the midwife across the UK and provides guidelines on care in relation to obesity and measuring height and weight on booking (Midwifery 2020, 2010). If the woman's BMI is more than 30 it is recommended that midwives discuss the risks and explore the woman's diet. Many Scottish regions emphasise continuity across antenatal care but often without continuity of carer; nor does this care, except in rare circumstances, traverse intrapartum and all postnatal care. The fragmented style of midwifery care for the majority of the Scottish population would seem at odds with providing individualised dietary advice. However, the health care culture and systems in Scotland are now evolving. A recent review of maternity and neonatal services (Scottish Government, 2017) recommended continuity of carer for all regions across Scotland within five years. Recommendation 1 out of 76 in the review states, "Every woman will have continuity of carer from a primary midwife who will provide the majority of their antenatal intrapartum and postnatal care..." (p.64). At the time of writing, early adopter sites have been identified that will work on implementing this priority recommendation across Scotland.

\section{Policy convergence and divergence between New Zealand and Scotland}

Policy responses converged in a number of areas. Maternal obesity remains a priority on the policy agendas of both New Zealand and Scotland. However, weight management interventions to address obesity in pregnancy are in their infancy in both countries. Written policy refers to obesity as a "societal problem" which goes beyond individual responsibility; the rationale being that obesity cannot be viewed simply as a health issue, nor will it be solved by reliance on individual behaviour change. Despite acknowledgement of the broader socio-environmental influences on health, New Zealand and Scottish policies continue to offer a narrow, medicalised, nonindividualised approach to healthy weight management.

Four areas of policy divergence were found. First, the Scottish Government has selected national indicators to monitor progress of the Prevention of Obesity Route Map (Scottish Government, 2010). A key indicator for children is to "reduce the rate of increase in the proportion of children with their body mass index outwith a healthy range by 2018" (Scottish Government, 2010, p.2). 
Subsequent to this, Scotland developed physical activity targets as an indicator for adults, aimed at increasing the proportion of adults reaching recommended levels of exercise (Musingarimi, 2009). In New Zealand, no similar targets have been identified for reducing child obesity or for increasing physical exertion.

Second, the New Zealand Childhood Obesity Plan (Ministry of Health, 2015b) directs midwives to use the national guidelines on healthy weight gain during pregnancy (Ministry of Health, 2014). No such guidelines have been published by the Scottish Government. In the UK, NICE (2010) failed to offer guidance with regard to what constitutes appropriate gestational weight gain, due to the uncertainty surrounding the recommendations available, particularly the widely used Institute of Medicine (IOM) guidelines (Poston, 2017; Scott et al., 2014). Consequently, while weighing women throughout pregnancy is not standard practice in Scotland, New Zealand practitioners are recommended to provide BMI specific advice to avoid excessive gestational weight gain.

Third, while New Zealand's obesity prevention policy is centred on a life-course approach for pregnant women, this is less evident in Scottish policy. In contrast, Scottish policy focuses less on early life interventions, leaning more toward environmental change.

Given the differences in ethnic group composition between New Zealand and Scotland, we might expect to see cross-national differences in policy making to support ethnic populations at high risk of obesity-related inequities. There is no such divergence. Despite the fact that Māori and Pacific peoples account for over $20 \%$ of the population in New Zealand and face a disproportionate health burden attributable to high rates of overweight and obesity (Theodore, McLean, \& TeMorenga, 2015), New Zealand policy fails to provide increased support for minority populations. Instead, the New Zealand Childhood Obesity Plan proposes increasing access to sporting opportunities for young people in communities where participation rates are low and the risk of poor health is consequently higher.

Recent evidence points to the loss of funding for Māori-led initiatives. This is described by Theodore et al. (2015) as a lost opportunity to identify the most effective interventions for improving health and reducing health inequities. This in turn, they say, represents a substantial risk to optimal Māori health, despite the responsibility of the New Zealand Government under the Treaty of Waitangi (New Zealand's founding document) to ensure Māori have at least the same standard of health as nonMāori (Medical Council of New Zealand, 2008). Paradoxically, the Childhood Obesity Plan has failed to gain support among Māori and Pacific peoples. Scotland, on the other hand, a country unaffected by obesity-related ethnic inequities, acknowledges the consequences of obesity and cautions health professionals to avoid approaches which "reflect, perpetuate and potentially increase social inequalities in health in Scotland" (Scottish Government, 2010, p.2).

From comparative exploration of the two countries' policies, it is evident that two themes are worthy of further discussion: the impact of models of midwifery care that focus on relationships and continuity of care and the role of the midwife within these countries.

\section{DISCUSSION}

The UK's Centre for Maternal and Child Enquiries, the Royal College of Obstetricians and Gynaecologists (Modder \& Fitzsimons, 2010) and NICE (2010) advise that all obese pregnant women be provided with accurate and accessible information about associated risks and how these may be minimised. They all recommend that obstetric care is prudent for women whose BMIs are more than $30 \mathrm{~kg} / \mathrm{m}^{2}$ rather than midwifery-led care. Yet caution needs to be taken not to pathologise the woman due to her weight alone. An individualised approach is called for that recognises the specific and complex contextual factors that impinge on the health status of all consumers, including pregnant women.

Both countries under review recognise the midwife as the key health professional; albeit the models of care are completely different otherwise in philosophy and practice arrangements. The one universal feature of both regimes is that, regardless of the model of care, all midwives promote woman-centred practice. Scottish midwifery services are currently fragmented compared to New Zealand's integrated services which are based on continuity of carer. In this context, fragmented care means that Scottish women receive care from community midwives who provide antenatal and postnatal care but rarely provide intrapartum care, other than the occasional primary birth either at home or, where available, at a stand-alone birth centre. Even when a primary/community birthing service is provided by community midwives, this is rarely by the named antenatal community midwife but whoever is on call at the time. In this way, fragmented care in Scotland refers to the fact that a named midwife does not follow the woman throughout her childbirth experience, as is the case for many New Zealand women who book with an LMC. The fragmented style of midwifery care for the majority of the Scottish population would seem at odds with providing individualised care. This fragmented experience has been highlighted in Cheyne et al.'s (2015) review of Scottish maternity experience, in which women frequently reported the dissatisfaction with having to repeat their story to different health care professionals throughout the childbirth experience. It is now rare that GPs and community midwives share pregnancy care in Scotland. Although many Scottish regions attempt midwifery continuity across antenatal care, they do not provide the degree of continuity across intrapartum and postnatal care as experienced by most New Zealand women. For the most part, in the Scottish context, community midwives provide a degree of continuity of care in pregnancy because antenatal clinics can be arranged around the off-duty entitlements of the community midwife. However, intrapartum care is unpredictable and postnatal care may fall over weekends when the rostered community midwife who provided the antenatal care is neither on call nor scheduled to work. In addition, the Scottish community midwife, unlike in New Zealand, does not follow the woman wherever her care is being provided. None of these community midwives, however, shares the same level of potential as the continuity of carer model in forging optimal midwife-woman relationships over time and, therefore, the facilitation of health promotion opportunities. As Scotland moves towards implementation of the Best Start recommendations for continuity of carer, it will be important to establish how evaluation of the continuity of carer service measures the standard that the service intends to achieve over time; e.g., "what does continuity of carer look like?" and "how will it be measured?" are very pertinent questions now needing to be answered as the implementation of the service rolls out across Scotland.

Treating each woman individually, that is, as a person with a unique combination of history, capacities, life-chances, opportunities and sociological characteristics based on gender, ethnicity, age, status, educational and religious affiliations, to mention just a few, not only better serves the woman herself, but also enables the LMC to offer specialised advice and support to facilitate optimal management and lifestyle changes, if necessary. It is an anathema to good health and a human rights agenda to simply label a woman as obese and treat her as personally irresponsible or incompetent just because this practice makes the UK nurse or midwife professionally 
compliant (Nursing and Midwifery Council, 2008). Referring to the UK midwives, Swann and Davies (2012) agree that midwives have a major public health role in addressing obesity, yet argue for individualistic care to help promote normal birth for obese women. As they state:

\section{The concept of the woman as expert in her own body, with the right to make informed decisions, is central to the midwifery model and should not be abandoned simply because risk factors are identified (p.11).}

The above commentary reflects the by now standard midwifery philosophy to always focus on the normal; although, as Scamell (2016) points out, tensions can arise when divergent care objectives are in conflict. In practice, therefore, managing risk while promoting normality is a reality for the majority of midwives who must perpetually guard against "the midwifery rhetoric of normal birth...[being]...devitalised by the hegemonic prioritisation of risk management and sensitivity" (Scamell, 2016, p.19).

Swann and Davies (2012) contend that more evidence is required to identify how midwifery care with obese women can improve their health outcomes. Evidence-based decisionmaking necessitates that midwives scrutinise the evidence, listen to women and deliver critically informed, woman-centred care recommendations; although, in our opinion, this may not be politically popular nor supported by the dominant medical group in most maternity domains.

Practice should be in line with best available evidence, but whose evidence? Ménage (2016) affirms a broader definition of evidence is required, including evidence derived from the woman, the midwife and research, alongside the environmental factors. The decision-making model developed by Ménage (2016) can assist midwives in considering and analysing evidence for decisionmaking in partnership with women, ensuring that, "the weighting of one piece of evidence over another is something that is discussed and negotiated within the woman-midwife partnership" (p.140). While further evaluation of the model is needed, this framework holds promise for a more respectful and equitable approach to risk assessment that better reflects the complex lived realities of women on low incomes.

A salient feature to emerge from obesity-targeted policies is an explosion of weight-focused discourses leading to increasing surveillance and focus on risk in contemporary maternity care. McGlone and Davies (2012) maintain that the BMI calculation was never intended for individual diagnosis, yet the pre-pregnant BMI has emerged as the standard measure to label women with a high BMI as "at risk" (McGlone \& Davies, 2012) and as a singular tool in "helping midwives to help obese pregnant women towards a healthier pregnancy" (Poston, 2017). The use of a standard BMI measurement fails to factor in women's complex histories, capacities and sociological characteristics. Further, reliance on BMI alone compromises the midwifery model of partnership which does appreciate complexities and forges collaboration between midwife and woman. Our aim is to endorse the view that obesity in pregnancy represents a multifaceted and complex social process and, although it has serious medical implications, the extent of these involves more than just calculation of BMI. Instead, we aim to stimulate debate on the reliability and validity of a blanket approach of using pre-pregnancy BMI as a tool for all women in assessing risk in a normal pregnancy.

Further, we warn against an uncritical ingestion of a discourse underpinning much BMI messaging leading to standardised care pathways in favour of a little publicised, countervailing discourse that gives a realistic appraisal of health at any size (Rowe \& Fisher, 2015). Unfortunately, although midwives are charged with enabling woman-centred, family-centred and culturally sensitive care, generic, biomedical health policies continue to dominate. The effect is to create an unstable relational space which challenges the professional/consumer partnership that could potentially flourish; a partnership which is foundational to the salutogenesis lying at the heart of midwifery practice. Ideally, midwives adopt the role of critic and conscience of maternity care; the challenge for midwifery being to locate itself more explicitly in a public health care context to better enable critique of the research which may impact upon women's experiences of care.

\section{STRENGTHS AND LIMITATIONS}

Our argument is made on the basis of a comparative analysis of health policy and models of care rather than on what women or midwives say about this, so caution needs to be taken in drawing conclusions. The paper contributes a description of the variations in policy contexts and maternity practice between New Zealand and Scotland and has highlighted important differences in the models of maternity care across these two countries. The opportunity to foreground divergent and convergent policy and practice across two different regions is a strength of this analysis because aspects worthy of further investigation (such as the voices of women and midwives) have been identified.

\section{CONCLUSION}

Midwifery philosophy has developed over time in contradistinction with medical philosophy to interpret pregnancy as a normal life event. The unintended consequences of health policies such as singular reliance on BMI to determine risk status have the potential to universally pathologise the individual, in this case to reinterpret pregnancy as a high risk life event. Hence, the use of BMI in maternity merits rigorous debate. The role of midwives extends beyond the provision of woman-centred care to the critique of emergent approaches and therefore promotes the autonomy of midwifery. We have shown that policies designed to regulate and diminish what has been called the obesity pandemic in Western countries have had the effect of directing midwives to undertake practices which are potentially detrimental to the midwifery partnership relationship based upon person-centredness and salutogenesis. The ongoing challenge for midwives is to drive improvements in health policies that are simultaneously congruent with the partnership model of midwifery practice. This may entail replacing a simplistic and singular medical indicator, such as BMI, with a composite indicator representing complex underlying factors unique to individual women. The value of this shift in policy would be an enhanced focus on outcomes that matter to individual women and better facilitate the management of overall health, including weight gain, before, during and after pregnancy. Congruence between health policy and midwifery practice is important if best practice and optimal outcomes are to be achieved.

Our paper is a small contribution to understanding the unintended consequences of health policy on midwifery practice. We point towards future possibilities for more effective approaches in maternity care. There are multiple influences that serve to shape government policy. We have highlighted how the BMI measure has become established in maternity care, yet its universal implementation and acceptance is unlikely to meet the needs of the majority of women. Policy which fails to consider the multiple and complex contexts of women's lives challenges the very nature of woman-centred practice which lies at the heart of midwifery practice in New Zealand and Scotland. 


\section{ACKNOWLEDGEMENTS AND CONFLICT OF INTEREST DISCLOSURE}

We thank Nicola Jackson, Registered Midwife in Wellington, who assisted in the review of this paper. The authors declare that there are no conflicts of interest.

\section{REFERENCES}

Adamo, K.B., Ferraro, Z.M., Goldfield, G., Keely, E., Stacey, D., Hadjiyannakis, S.,... Barrowman, N.J. (2013). The Maternal Obesity Management (MOM) Trial Protocol: A lifestyle intervention during pregnancy to minimize downstream obesity. Contemporary Clinical Trials, 35(1), 87-96.

Bacon, L., \& Aphramor, L., (2011). Weight science: Evaluating the evidence for a paradigm shift. Nutrition Journal, 10(9), 2-13.

Cain, R. (2013). 'This growing genetic disaster': Obesogenic mothers, the obesity 'epidemic'and the persistence of eugenics. Studies in the Maternal, 5(2), 1-24.

Catalano, P., \& Ehrenberg, H. (2006). Review article: The short- and long-term implications of maternal obesity on the mother and her offspring. BJOG: An International Journal of Obstetrics and Gynaecology, 113(10), 1126-1133.

Chen, A., Feresu, S.A., Fernandez, C., \& Rogan, W.J. (2009). Maternal obesity and the risk of infant death in the United States. Epidemiology, 20(1), 74-81.

Cheyne, H., Critchley, A., Elders, A., Hill, D., Milburn, E., \& Paterson, A. (2015). Having a Baby in Scotland 2015: Listening to Mothers National Report. Edinburgh, Scotland: Scottish Government.

Denison, F., Norwood, P., Bhattacharya, S., Duffy, A., Mahmood, T., Morris, C.,...Scotland, G. (2014). Association between maternal body mass index during pregnancy, short-term morbidity, and increased health service costs: A population-based study. BJOG: An International Journal of Obstetrics and Gynaecology, 121(1), 72-81.

Dodd, J.M., Grivell, R.M., Nguyen, A.M., Chan, A., \& Robinson, J.S. (2011). Maternal and perinatal health outcomes by body mass index category. Australian and New Zealand Journal of Obstetrics and Gynaecology, 51(2), 136-140.

Essington, M., \& Hertelendy, A.J. (2016). Legislating Weight Loss: Are Antiobesity Public Health Policies Making an Impact? Journal of Health Politics, Policy and Law, 41(3), 453-461.

Furber, C.M., McGowan, L., Bower, P., Kontopantelis, E., Quenby, S., \& Lavender, T. (2013). Antenatal interventions for reducing weight in obese women for improving pregnancy outcome, Cochrane Database of Systematic Review, Jan 31(1), 1-26.

Galtier, F., Raingeard, I., Renard, E., Boulot, P., \& Bringer, J.

(2008). Optimizing the outcome of pregnancy in obese women: From pregestational to long-term management. Diabetes \& Metabolism, 34(1), 19-25.

Galtier-Dereure, F., Boegner, C., \& Bringer, J. (2000). Obesity and pregnancy: Complications and cost. The American Journal of Clinical Nutrition, 71(5), 1242s-1248s.

Gilmore, L.A., Klempel-Donchenko, M., \& Redman, L.M. (2015). Pregnancy as a window to future health: Excessive gestational weight gain and obesity. Seminars in Perinatology, 39(4), 296-303.

Greener, J., Douglas, F., \& van Teijlingen, E. (2010). More of the same? Conflicting perspectives of obesity causation and intervention amongst overweight people, health professionals and policy makers. Social Science \& Medicine, 70(7), 1042-1049.

Hall, P., \& Cole, T. (2006). What use is the BMI? Archives of Disease in Childhood, 91(4), 283-296.

Hafekost, K., Lawrence, D., Mitrou, F., O'Sullivan, T.A., \& Zubrick, S.R. (2013). Tackling overweight and obesity: Does the public health message match the science? BMC Medicine, 11(1), 41.

Heslehurst, N., Moore, H., Rankin, J., Ells, L.J., Wilkinson, J.R., \& Summberbell, C.D. (2011). How can maternity services be developed to effectively address maternal obesity? A qualitative study. Midwifery, 27(5), e170-e177.

Hill, B., McPhie, S., Moran, L.J., Harrison, P., Huang, T.T.-K., Teede, H., \& Skouteris, H. (2017). Lifestyle intervention to prevent obesity during pregnancy: Implications and recommendations for research and implementation. Midwifery, 49, 13-18.

Huda, S.S., Brodie, L.E., \& Sattar, N. (2010). Obesity in pregnancy: Prevalence and metabolic consequences. Seminars in Fetal and Neonatal Medicine, 15(2), 70-76.
Inhorn, M.C., 2006. Defining women's health: A dozen messages from more than 150 ethnographies. Medical Anthropology Quarterly, 20(3), 345-378

Institute of Medicine, \& National Research Council. (2009). Weight Gain During Pregnancy: Re-examining the Guidelines. In A.L. Yaktine \& K.M. Rasmussen (Eds). Washington DC, USA: National Academies Press.

International Confederation of Midwives. (2017a). Position Statement on Appropriate Maternity Services for Normal Pregnancy, Childbirth and the Postnatal Period. Retrieved from http://internationalmidwives. $\mathrm{org} /$ who-we-are/policy-and-practice/icm-position-statements-general/ International Confederation of Midwives. (2017b). Position Statement on Partnership between Women and Midwives. Retrieved from http:// internationalmidwives.org/who-we-are/policy-and-practice/icm-positionstatements-general/

Jarvie, R. (2017). Lived experiences of women with co-existing BMI $\geq 30$ and Gestational Diabetes Mellitus. Midwifery, 49, 79-86.

Kan, M.Y., \& Lau, M. (2013). Comparing alcohol affordability in 65 cities worldwide. Drug and Alcohol Review, 32(1), 19-26.

Keely, A., Cunningham-Burley, S., Elliott, L., Sandall, J., \& Whittaker, A. (2017). "If she wants to eat... and eat and eat... fine! It's gonna feed the baby": Pregnant women and partners' perceptions and experiences of pregnancy with a BMI $>40 \mathrm{~kg} / \mathrm{m}^{2}$. Midwifery, 49, 87-94.

Kohn, M.L. (1989). Cross-national Research in Sociology. Newbury Park, USA: Sage Publications.

Koniak-Giffin, D. (1993). Maternal role attainment. Journal of Nursing Scholarship, 25, 257-262.

Lashen, H., Fear, K., \& Sturdee, D. (2004). Obesity is associated with increased risk of first trimester and recurrent miscarriage: Matched casecontrol study. Human Reproduction, 19(7), 1644-1646.

Leslie, W., Gibson, A., \& Hankey, C. (2013). Prevention and management of excessive gestational weight gain: A survey of overweight and obese pregnant women. BMC Pregnancy and Childbirth, 13(1), 1-16.

Lindhardt, C.L., Rubak, S., Mogensen, O., Lamont, R.F., \& Joergensen, J.S. (2013). The experience of pregnant women with a body mass index $>30 \mathrm{~kg} / \mathrm{m}^{2}$ of their encounters with healthcare professionals. Acta Obstetricia et Gynecologica Scandinavica, 92(9), 1101-1107.

Marchi, J., Berg, M., Dencker, A., Olander, E.K., Begley, C. (2015). Risks associated with obesity in pregnancy, for the mother and baby: A systematic review of reviews. Obesity Reviews, 16(8), 621-638.

McGlone, A., \& Davies, S. (2012). Perspectives on risk and obesity: Towards a 'tolerable risk' approach? British Journal of Midwifery, 20(1), 13-17.

Medical Council of New Zealand. (2008). Best Health Outcomes for Mãori: Practice Implications. Wellington: Author.

Ménage, D. (2016). Part 2: A model for evidence-based decision-making in midwifery care. British Journal of Midwifery, 24(2), 137-143.

Midwifery 2020. (2010). Midwifery 2020: Delivering expectation. Cambridge, UK: Author

Mills, A., Schmied, V.A., \& Dahlen, H.G. (2013). 'Get alongside us', women's experiences of being overweight and pregnant in Sydney, Australia. Maternal \& Child Nutrition, 9(3), 309-321.

Mills, C.W. (1959). The Sociological Imagination. Oxford, England Oxford University Press.

Ministry of Health. (2006). Food and nutrition guidelines for healthy pregnant and breastfeeding women. Wellington: Author.

Ministry of Health. (2012). Guidelines for Consultation with Obstetric and Related Medical Services (Referral Guidelines). Wellington: Author. Ministry of Health. (2014). Guidance for Healthy Weight Gain in Pregnancy. Wellington: Author.

Ministry of Health. (2015a). Annual Update of Key Results 2014/15: New Zealand Health Survey. Wellington: Author.

Ministry of Health. (2015b). Childhood Obesity Plan. Retrieved from https://www.health.govt.nz/our-work/diseases-and-conditions/obesity/ childhood-obesity-plan.

Ministry of Health. (2016). New Zealand Health Strategy: Roadmap of actions 2016. Retrieved from https://www.health.govt.nz/system/files/ documents/publications/new-zealand-health-strategy-roadmapofactions2016-apr16.pdf

Modder, J., \& Fitzsimons, K.J. (2010). Joint Guidelines for the Management of Women with Obesity in Pregnancy. England: Centre for Maternal and Child Enquiries, \& Royal College of Obstetricians and Gynaecologists. 
Mooney, J.D., Jepson, R., Frank, J., \& Geddes, R. (2015). Obesity prevention in Scotland: A policy analysis using the ANGELO framework. Obesity Facts, 8(4), 273-281.

Morad, S., Parry-Smith, W., \& McSherry, W. (2013). Dignity in Maternity Care. Evidence Based Midwifery, 11(2), 67-70.

Mourtakos, S.P., Tambalis, K.D., Panagiotakos, D.B., Antonogeorgos, G., Arnaoutis, G., Karteroliotis, K., \& Sidossis, L.S. (2015). Maternal lifestyle characteristics during pregnancy, and the risk of obesity in the offspring: A study of 5,125 children. BMC Pregnancy \& Childbirth, 15(1), 1 .

Musingarimi, P. (2009). Obesity in the UK: A review and comparative analysis of policies within the devolved administrations. Health Policy, 91(1), 10-16

National Institute Health and Clinical Excellence. (2010). Weight management before, during and after pregnancy. Retrieved from https:// www.nice.org.uk/guidance/ph27

Nursing and Midwifery Council. (2008). The Code: Standards, Performance and Ethics for Nurses and Midwives. Retrieved from https:// www.nmc.org.uk/standards/codel

Pan, S., Dixon, L., Paterson, H., \& Campbell, N. (2014). New Zealand LMC midwives' approaches to discussing nutrition, activity and weight gain during pregnancy. New Zealand College of Midwives Journal, 50, 24-29.

Pirkola, J., Pouta, A., Bloigu, A., Hartikainen, A.-L., Laitinen, J., Järvelin, M.-R., \& Vääräsmäki, M. (2010). Risks of overweight and abdominal obesity at age 16 years associated with prenatal exposures to maternal prepregnancy overweight and gestational diabetes mellitus. Diabetes Care, 33(5), 1115-1121.

Poston, L. (2017). Obesity in pregnancy; Where are we, where should we go? Midwifery, 49, 4-6.

Ramachenderan, J., Bradford, J., \& McLean, M. (2008). Maternal obesity and pregnancy complications: A review. Australian and New Zealand Journal of Obstetrics and Gynaecology, 48(3), 228-235.

Room, R., Bloomfield, K., Gmel, G., Grittner, U., Gustafsson, N.-K., Mäkelä, P.,... Wicki, M. (2013). What happened to alcohol consumption and problems in the Nordic countries when alcohol taxes were decreased and borders opened? The International Journal of Alcohol and Drug Research, 2(1), 77-87.

Rowe, H.J., \& Fisher, J.R.W. (2015). Do contemporary social and health discourses arouse peripartum anxiety? A qualitative investigation of women's accounts. Women's Studies International Forum, 51, 56-65.

Rowland, T., McLeod, D., \& Forese-Burns, N. (2012). Comparative Study of Maternity Systems. Wellington: Ministry of Health.

Ryan, D. (2007). Obesity in women: A life cycle of medical risk. International Journal of Obesity., 31, S3-S7.

Scamell, M. (2016). The fear factor of risk-clinical governance and midwifery talk and practice in the UK. Midwifery, 38, 14-20.

Scott, C., Andersen, C.T., Valdez, N., Mardones, F., Nohr, E.A., Poston, L.... Abrams, B. (2014). No global consensus: a cross-sectional survey of maternal weight policies. BMC Pregnancy \& Childbirth, 14(1), 167.

Scottish Government. (2010). Preventing overweight and obesity in Scotland: A route map towards healthy weight. Edinburgh, Scotland: Author.

Scottish Government. (2011). Improving Maternal and Infant Nutrition: A Framework for Action. Edinburgh, Scotland: Author.

Scottish Government. (2015). The Scottish Health Survey 2014.

Edinburgh, Scotland: Author

Scottish Government. (2017). The best start: A five year forward plan for maternity and neonatal care in Scotland. Edinburgh, Scotland: Author.

Shield, K.D., Rylett, M., Gmel, G., Gmel, G., Kehoe-Chan, T.A., \& Rehm, J. (2013). Global alcohol exposure estimates by country, territory and region for 2005-a contribution to the Comparative Risk Assessment for the 2010 Global Burden of Disease Study. Addiction, 108(5), 912-922.

Smith, D.M., Taylor, W., Whitworth, M.K., Roberts, S., Sibley, C., \& Lavender, T. (2015). The feasibility phase of a community antenatal lifestyle programme [The Lifestyle Course (TLC)] for women with a body mass index (BMI) $\geq 30 \mathrm{~kg} / \mathrm{m}^{2}$. Midwifery, 31(2), 280-287.

Stotland, N.E. (2009). Obesity and pregnancy. BMJ, 338, 107-110. Sutherland, G., Brown, S., \& Yelland, J. (2013). Applying a social disparities lens to obesity in pregnancy to inform efforts to intervene. Midwifery, 29(4), 338-343.
Swann, L., \& Davies, S. (2012). The role of the midwife in improving normal birth rates in obese women. British Journal of Midwifery, 20(1). Theodore, R., McLean, R., \& TeMorenga, L. (2015). Challenges to addressing obesity for Māori in Aotearoa/New Zealand. Australian and New Zealand Journal of Public Health 39(6), 509-512.

Torloni, M.R., Betran, A.P., \& Merialdi, M. (2012). Demography of Obesity. In M.W. Gillman, \& L. Poston (Eds.), Maternal Obesity (pp.15). New York, USA: Cambridge University Press.

Warren, L., Rance, J., \& Hunter, B. (2017). Eat Well Keep Active: Qualitative findings from a feasibility and acceptability study of a brief midwife led intervention to facilitate healthful dietary and physical activity behaviours in pregnant women. Midwifery, 49, 117-123.

World Health Organization. (2015a). Interim Report of the Commission on Ending Childhood Obesity. Geneva, Switzerland: Author.

World Health Organization. (2015b). Overweight and Obesity Fact Sheet. Retrieved from http://www.who.int/news-room/fact-sheets/detail/ obesity-and-overweight

Yeo, S., \& Logan, J.G. (2014). Preventing obesity: Exercise and daily activities of low-income pregnant women. Journal of Perinatal \& Neonatal Nursing, 28(1), 17-25.

Zadoroznyj, M. (1999). Social class, social selves and social control in childbirth. Sociology of Health \& Illness, 21(3), 267-289.

\section{Accepted for Publication June 2018}

Knox, S., Crowther, S., McAra-Couper, J., \& Gilkison, A. (2018). Health policy and its unintended consequences for midwife-woman partnerships: Is normal pregnancy at risk when the BMI measure is used? New Zealand College of Midwives Journal, 54, 30-37.

https://doi.org/10.12784/nzcomjnl54.2018.4.30-37 